\title{
The role of faculty advisors in preceptorship: From a faculty point of view
}

\author{
Florence Loyce Luhanga ${ }^{* 1}$, Koren Irene ${ }^{2}$, Olive Yonge ${ }^{3}$, Florence Myrick ${ }^{3}$ \\ ${ }^{1}$ Faculty of Nursing, University of Regina, Regina, Canada \\ ${ }^{2}$ School of Nursing, Laurentian University, Sudbury, Canada \\ ${ }^{3}$ Faculty of Nursing, University of Alberta, Edmonton, Canada
}

Received: August 13, 2014

DOI: $10.5430 /$ jnep.v5n1p85
Accepted: October 27, $2014 \quad$ Online Published: November 3, 2014

URL: http://dx.doi.org/10.5430/jnep.v5n1p85

\begin{abstract}
Objective: The purpose of this study was twofold: 1) to explore the psychosocial process involved when senior baccalaureate students were being evaluated as unsafe by their preceptors; and 2) to understand how faculty play a role in that process.

Method: A grounded theory method was employed. Data were generated from six faculty via semi-structured interviews and analyzed using constant comparative analysis.

Results: The process of 'Facilitating student success' emerged as the core variable. Intrinsic to this process were six major categories and their inherent subcategories: 1) recognizing red flags of unsafe practice; 2) strategies for managing students who display unsafe practice; 3) using evaluation strategies to foster success; 4) deciding to fail a student; 5) guiding and supporting the student and preceptor; and 6) guiding and supporting faculty. The six major categories represent the processes that faculty advisors used to facilitate student learning and success in the clinical setting. In this article, only findings related specifically to the last category 'Guiding and supporting faculty', and subcategories: 'role preparation', 'faculty advisor perceived roles', and 'guidance and support received from the educational program' will be discussed. The other categories have been reported elsewhere.

Conclusion: The findings from this study can contribute to our understanding of: a) the process involved in working with final year nursing students who display unsafe clinical practice; b) identifying preparatory and support needs of faculty who oversee the preceptorship experience; and c) the value of the development and implementation of preceptorship support programs.
\end{abstract}

Key Words: Preceptorship, Unsafe nursing students, Grounded theory, Faculty advisors, Preparation and roles

\section{Introduction}

The preceptorship model of clinical education is used extensively in Canadian baccalaureate nursing programs primarily for senior level students and especially for the final practicum. ${ }^{[1,2]}$ The conventional preceptorship model is a teaching-learning triad comprised of a Registered Nurse preceptor employed by a practicum agency, a nursing stu- dent and a representative of the educational program (faculty advisor). ${ }^{[3-5]}$ The success of the preceptorship is based on the strength of the triad relationship. ${ }^{[2,4]}$ From the preceptor perspective, faculty support and guidance are crucial particularly when critical decisions regarding student competence and ultimate preparation for registration are in question. [6]

\footnotetext{
*Correspondence: Florence Loyce Luhanga; Email: florence.luhanga@ uregina.ca; Address: Faculty of Nursing, Research and Innovation Centre, University of Regina, Regina, Saskatchewan, Canada.
} 
In this study setting, the final practicum course consisted of 360 hours. The preceptorship team included the course professor, the faculty advisor, the preceptor and the final year student. The course professor was responsible for: directing and supporting the teaching/learning process, ensuring that the practicum was appropriate for the acquisition of the $\mathrm{BScN}$ program objectives, and the preceptorship team was adequately prepared for the experience. The course professor was also responsible for ensuring that the student had the opportunity to meet the objectives of the practicum and was evaluated in accordance with the program goals, as well as determining the students' final course grade. The faculty advisor, unlike the course professor, was a full faculty member or a part-time educator with an appointment in the School of Nursing who was responsible for directly assisting the student with the development of a clinical learning plan, promoting student reflection on practice and the application of theory to enhance critical thinking, and overseeing the student's progress toward achieving the learning outcomes.

Although the faculty advisor did not usually work with the preceptor-student dyad on a day-to-day basis, the faculty advisor was the link between the nursing education program and the clinical practicum setting and was responsible for directing the teaching and learning process for the course professor. ${ }^{[2,3,5,7]}$ As the custodian of the teaching and learning process and final evaluator of student outcomes in the clinical practicum, the faculty advisor was required to: a) respond to any concerns from and provide support to both the preceptor and the student; and b) assume the ultimate responsibility for determining whether the student has met the program outcomes and acquired the competencies to enter the nursing profession.

While it is assumed that faculty advisors have the requisite knowledge and skills required for deciding student achievement of course objectives ${ }^{[8]}$ there is evidence in the literature that many faculty advisors are not academically prepared to teach and evaluate the clinical component of nursing education programs, particularly in preceptorship-based clinical courses. ${ }^{[4,7,9]}$

To maintain professional standards, faculty advisors are therefore expected to be able to identify indicators of satisfactory clinical performance, recognize when these indicators are not met, and then follow through with appropriate action to address the deficit. Identification and intervention are critical processes in working with and managing students who are unsafe or whose clinical performance is marginal or failing to meet the program objectives. ${ }^{[10-12]}$ Many faculty advisors, however, may have difficulty in identifying students with unsafe practices and particularly in making appropriate decisions regarding unsafe performance. ${ }^{[11,13,14]}$

Multiple interpretations of what constitutes 'unsafe practice' and the absence of guidelines for response reflect the complexity of the issue. ${ }^{[11,13,14]}$ In this study, unsafe student practice was defined relative to program outcomes. Unsafe practices included an act or behaviour by the student that reflected a lack of knowledge, skills, or clinical judgement, or any unprofessional or unethical conduct that in a way threatened or had the potential to threaten the physical, emotional, mental or environmental safety of the patient, self or other health care personnel. ${ }^{[6,14]}$ To date, there is little in the literature as to how faculty advisors actually respond to senior nursing students who are assessed in their final clinical practicum as being unsafe, marginal, or failing to meet course objectives or program outcomes.

Consequently, owing to the importance of the role of faculty advisors in the preceptorship approach to clinical teaching and learning, the purpose of this study was to generate data that would lead to greater understanding of the processes in which faculty advisors engage when working with final year nursing students who have been assessed as being unsafe in nursing practice by their preceptors. In particular, in this paper we report on faculty advisors' perceptions of (a) their preparation for their role in preceptorship-based courses, and (b) resources and supports, essential for advisors and preceptors, to facilitate the management of students who are assessed as unsafe, marginal or who fail to meet course objectives/program outcomes.

\subsection{Literature review}

\subsubsection{Faculty advisor role and responsibilities in precep- torship}

The role of the faculty advisor is pivotal to the success of the preceptorship experience. ${ }^{[2-6]}$ Faculty advisors bring a wealth of knowledge, resources and insight into the teaching and learning environment. ${ }^{[2,5]}$ They "contribute a strong practice education partnership that promotes safe client care, sustains placements, and fosters scholarship". ${ }^{[5]}$ As the liaison between the academic and practicum setting the faculty advisor is available to the student and preceptor to: provide guidance and support as needed; to conduct frequent visits to the practicum setting to ensure congruency among student learning objectives, preceptor practicum expectations, and program educational goals; respond to concerns raised by the student or preceptor; and assume ultimate responsibility for the final evaluation and grading of a student's clinical practicum performance..$^{[2,3,5,7-9]}$

Myrick and Yonge ${ }^{[2]}$ further explain that because of their role as custodians of the teaching/learning process and their ultimate responsibility for the final evaluation of the preceptored students, faculty advisors must be diligent and consistent in their efforts to communicate with both the preceptor and the student. Other authors also emphasize the importance of communication among faculty advisors and preceptors regarding the clinical evaluation of students..$^{[3,7]}$ For example, Corlette ${ }^{[15]}$ found that preceptors perceived in- 
adequate communication, relationship building, or information exchange between educational institutions and practice settings as challenges to preceptorship models. Invariably, authors acknowledge that maintaining communication with preceptors can be a challenge for some faculty advisors, particularly when preceptors are geographically distant from the university. ${ }^{[5,16]}$ As well, a high student-advisor ratio can also contribute to this particular challenge. Regardless of these challenges, faculty advisors are responsible for the preparation of students and preceptors; they need to understand the role of the preceptor so they can accurately convey the expectations of the preceptor to the student. ${ }^{[4,17]}$

\subsubsection{Faculty advisors and the challenges of student evaluation in the clinical setting}

Within the context of preceptorship, clinical evaluation of student performance is particularly challenging for faculty advisors because they rarely directly observe or supervise student performance. ${ }^{[8,9]}$ Rather, faculty rely on the preceptor observations to make judgements about the student's ability to achieve the clinical objectives which, in turn, can be of great concern for some students ${ }^{[8,18]}$ in particular for those who are at risk of failing. ${ }^{[8,19]}$ Without direct supervision, some faculty advisors require a mechanism by which to monitor student progress. ${ }^{[9]}$ The faculty advisor may find it difficult to fail a student for actions the faculty was not able to observe directly. Furthermore, faculty advisors may be reluctant to judge performance that they have not repeatedly observed and may therefore give students the benefit of the doubt to avoid grievance processes. ${ }^{[9]}$

The issue of reluctance to fail unsafe or incompetent students has been documented by a number of scholars in nursing. ${ }^{[10,12,20]}$ For example, faculty advisors who lack knowledge, experience or confidence in the evaluation role are reluctant to fail unsafe or marginal students. ${ }^{[9,12,14,20]}$ In addition, few schools of nursing have written policies or guidelines for faculty advisors to follow when dealing with unsafe students. ${ }^{[13,14,21]}$ Walsh and Seldomridge ${ }^{[21]}$ examined the relationship between 10 pairs of didactic and clinical courses at one university from 1997 to 2002 and found a marked disparity between didactic and clinical grades, with clinical grades being much higher. They further identified that criteria for clinical grading were not clear and were open to great subjectivity. In another study, Amiccuci ${ }^{[22]}$ explored the lived experience of grading clinical performance for experienced clinical nurse faculty in prelicensure programs. For these faculty, it was found that subjectivity was valued and the cause for thoughtful consideration. ${ }^{[22]}$

\subsubsection{Faculty advisors' preparation for their role in pre- ceptorship}

Faculty advisors' preparation for their role in preceptorship is important for a positive practicum. ${ }^{[4,7,23]}$ Indeed, faculty advisor preparation is important not only to preceptor

Published by Sciedu Press preparation and student teaching/learning but also to preceptor support and guidance, especially when the preceptor is faced with making critical decisions about a student who is unsafe. ${ }^{[6]}$ In the literature review, it was revealed however, that the issue of faculty advisor preparation for the preceptorship based-courses has not been adequately addressed regardless of its relevance to the success of the preceptorship experience.

Invariably, the literature is replete with studies exploring preceptorship from the perspective of preceptors and students. $^{[3,19,24]}$ More recently, Zawaduk et al. ${ }^{[5]}$ explored faculty-informed practices that promote relationships among the triad in preceptorships. These include attending to distant relationships, being cognizant of the influences of continuity, recognizing a preceptor's proficiency, responding to rapidly changing and complex environments, facilitating common understanding through communication and integrating practice and educational performance expectations (p. 214).

Only one study ${ }^{[7]}$ was found in which faculty perceptions was explored regarding their preparation for the preceptorship experience. In 2003, Yonge et al. ${ }^{[7]}$ explored the issue of faculty advisor preparation to teach in preceptorshipbased courses. The participants in this study reported inconsistency in their preparation, and some felt unprepared. The faculty indicated that they had little knowledge about the preceptors, inadequate information to provide preceptors, unawareness of student expectations, and limited support from colleagues during the final evaluation of student performance. They further reported that they had no orientation to the course and therefore learned their role primarily by trial and error or by observing experienced faculty advisors in the clinical setting.

Consistent with previous findings ${ }^{[25]}$ faculty advisors who believed they were well prepared attributed it to reading research, attending presentations or meetings, leading workshops, preceptoring students previously, interacting with other faculty, and being familiar with the practice setting. ${ }^{[7]}$ In light of the fact that the ultimate responsibility for preceptor preparation, as well as grading of student performance rests directly with faculty advisors, Yonge et al. ${ }^{[7]}$ concluded that faculty advisors require sufficient preparation to facilitate preceptorship-based courses. Without proper faculty advisor preparation, the subsequent preparation of preceptors and students will continue to be inconsistent. ${ }^{[23]}$ As educators, we therefore believe there is a need for further research in this area to determine the preparatory and support needs of faculty advisors to effectively facilitate the preceptorship experience and to identify the processes they use in dealing with difficult or challenging situations, particularly those circumstances in which a student's level of performance is borderline or unsafe. 


\section{Method}

\subsection{Design}

Owing to the lack of research on preceptorship and faculty perception of their preparation for the faculty advisor role and the process in which they engage when dealing with a student who engages in unsafe clinical practice or demonstrates marginal clinical competence, a grounded theory study ${ }^{[26]}$ was considered the most appropriate method for this study. Grounded theory allowed the researchers to uncover the main concerns of faculty advisors and to identify exactly how they engaged in the process of managing such concerns.

\subsection{Sample and setting}

Nursing faculty involved in the teaching of preceptorshipbased courses were informed about the study via the faculty website shared by a collaborative Bachelor of Science in Nursing $(\mathrm{BScN})$ nursing program in eastern Canada. The inclusion criteria were as follows: a) the ability to speak English, and b) involvement in a structured preceptorship with fourth year level baccalaureate nursing students either as a course professor or faculty advisor. The sample comprised six faculty members. Four held the position of faculty advisor while two reported having dual roles as course professor and faculty advisor. Four of the participants taught at a college while two taught at the university. All participants were female with a graduate level education. Five participants were prepared at the master's level and one at the doctoral level. Participants indicated that they had from 22 to 40 years of nursing practice experience and $11 / 2$ years to 25 years of teaching in nursing education.

\subsection{Data collection}

Data were collected primarily through individual semistructured interviews with faculty advisors that ranged between 40-90 minutes. As data were collected from a geographically dispersed sample, a graduate research assistant interviewed three participants by phone and three by faceto-face interview. Prior to taping interviews, demographic data were obtained from all the participants. Guiding interview questions included but were not limited to the following:

(1) Describe how you were prepared for your role in the preceptorship experience.

(2) How do you engage with a student who has been assessed as unsafe by a preceptor?

(3) Describe the kind of guidance or support you receive from your educational program?

Secondary data sources included reviews of the preceptorship resource manual and preceptor-based course outlines. It was assumed that a mixed approach to data collection would provide richer data than a single approach.

\subsection{Data analysis}

Each interview was audio taped and transcribed verbatim by the research assistant. In accordance with Glaser's (1978) grounded theory method, constant comparative analysis was undertaken. ${ }^{[26,27]}$ The first and second author independently analysed all the data and met several times to reach a consensus on the coding process and emerging themes. Data analysis began simultaneously with commencement of data collection and was achieved through the processes of: a) substantive coding, which includes both open and selective coding; and b) theoretical coding. During open coding a line by line analysis of data proceeded. This process involved reading the data several times, identifying key words or phrases, patterns or events and carefully comparing them with subsequent transcripts in which similar words, phrases, ideas, or associations occurred. ${ }^{[27]}$ This open coding process generated the substantive codes or categories and their attributes. These reflected 'student success,' being present, facilitating', 'supporting,' faculty perceived role,' 'strategies for success,' 'evaluation strategies for success,' and 'guidance and support.' The substantive codes were sorted into broader categories a process which continued until we had identified the faculty advisors' main concern. We then could identify the core category that actually captured how they managed this concern (see Figure 1). In the next level of analysis, we concentrated on modifying categories and integrating existing theory with the categories and subcategories that emerged. ${ }^{[28]}$ Thereafter, through theoretical coding, a process which relates the concepts of the theory to each other specifically at a more abstract level, we found theoretical saturation. As well, through routine memoing, categories were created and refined which in turn also served to shape the emerging theory. Journaling was also judiciously recorded throughout to safeguard against the influence of researcher bias.

\subsection{Ethical considerations}

Ethical approval was granted by the university's research ethics review board. Informed consent was obtained from each participant to be interviewed and audio taped. Participants were reminded that they could chose to withdraw from the study at any time without consequence. To ensure confidentiality, the names of participants were removed from all tape recordings, transcripts and field notes, and replaced with code numbers. All data were retained in a locked cabinet. Upon completion of the study, records with participant demographic information were shredded, and tapes and electronic records were destroyed in a secure manner.

\subsection{Rigour}

The four criteria of credibility, fittingness, auditability and conformability ${ }^{[29]}$ were maintained to ensure rigor or trustworthiness of the study. Credibility was achieved through peer debriefing and member checking. ${ }^{[30]}$ Fittingness was 
determined by asking independent experts to review and comment on the findings. Excerpts from participant transcripts are presented to facilitate auditability of data analysis and findings. ${ }^{[30]}$ As well, the researchers documented a comprehensive audit trail and recorded their theoretical memos to facilitate auditability and confirmability. ${ }^{[31]}$ The criterion of confirmability was achieved when credibility, fittingness, and auditiability were established. ${ }^{[32]}$

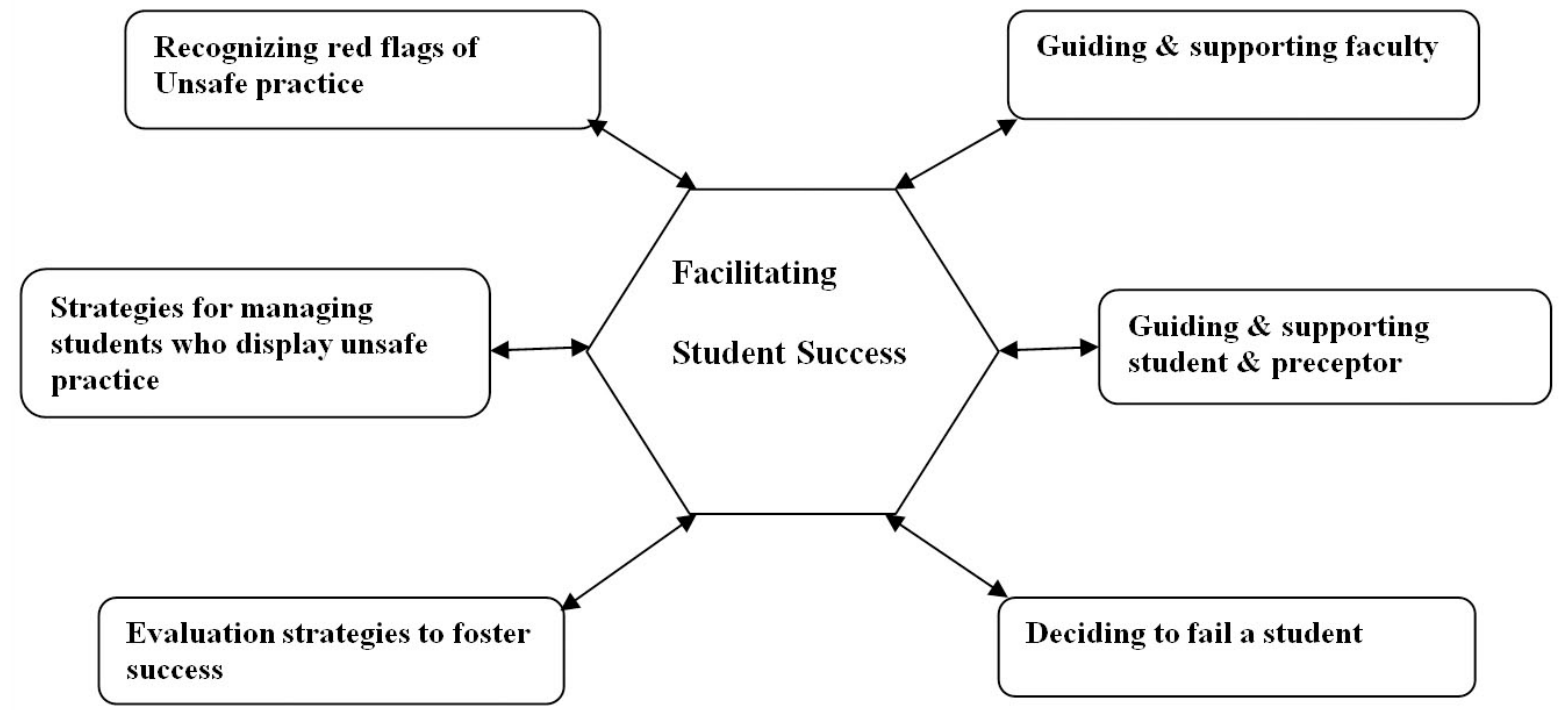

Figure 1: The core variable and six major categories

\section{Results}

As illustrated in Figure 1 above, the process of 'Facilitating student success' emerged as the core variable and reflects the concern for faculty advisors in this study as they worked with students who had been assessed as unsafe by their preceptors. Intrinsic to this process were six major categories and their inherent subcategories: 1) recognizing red flags of unsafe practice; 2) strategies for managing students who display unsafe practice; 3) using evaluation strategies to foster success; 4) deciding to fail a student; 5) guiding and supporting the student and preceptor; and 6) guiding and supporting faculty. The six major categories represent the processes that faculty advisors used to facilitate student success. In this article, only findings related specifically to the last category 'Guiding and supporting faculty,' and subcategories: 'role preparation', 'faculty advisor perceived roles', and 'guidance and support received from the educational program', will be discussed. The other categories have been reported elsewhere.

\subsection{Role preparation}

Regarding role preparation, participants in this study were asked to describe how they were prepared for their role as a faculty advisor in preceptorship. All participants reported having received no formal preparation for their role but rather described a variety of processes or activities through which they learned the role. These were characterized as follows: previous experiences as a nurse, experiences as a preceptor, experiences as a clinical educator, trial and error on the job, reading and accessing course related material, accessing web modules; as evidenced by the following participant comments:

"We really didn't have a lot of formal preparation. They just passed it on and assigned you this workload... Since then, I've read literature on different things and from experience. Trial and error on what works and what doesn't work..."

"I have also, during my career as a nurse, been a preceptor to other nurses..."

“... I often have been the faculty advisor, I have also had clinical groups in first year over the years, and preparation for that is just being a practicing nurse and being a faculty member here and understanding and knowing what the program is and the expectations, and what are the expectations of the College of Nurses. So, there really wasn't any formal preparation."

Furthermore, participants in this study reported that whenever necessary they asked for assistance from colleagues, course leaders, or program coordinators who were familiar with the preceptorship-based courses; as illustrated in the following participant's words: 
"I guess just having talked to other professors who had done the role of faculty advisor".

One participant indicated how she had prepared for her role as a faculty advisor through reading the online preceptorship training manual and "Some of the [professional Association's] Best Practice Guidelines" which she found very helpful.

\subsection{Faculty advisor perceived roles}

Participants in this study described facilitation of student success as fundamental to their role. Specific elements identified with this role reflected by faculty advisors included facilitating learning, facilitating communication, evaluating, and assigning the final grade. As one participant expressed:

“... I see my role as a facilitator and a supporter that is to facilitate the learning that is happening for the students, to facilitate the students but also to facilitate the preceptors in their role, to support them in that role."

Furthermore, participants in this study acknowledged the importance of communicating with preceptors. This category emerged in a variety of ways including but not limited to the faculty advisor: providing contact information; meeting with students; contacting the preceptor when the student commenced the placement; connecting with the preceptor and student when issues arose; encouraging open communication; being present and being involved when needed; making site visits as required; and being the liaison between the course professor and preceptor. As one participant explained:

[Whether] I'm a faculty advisor or a professor in a course where I have preceptors assigned, I really make an effort to contact them right away, let them know who I am, how they can get in touch with me, what my role is; if they have concerns, they can get back to me by email or phone or whatever, and that I will connect with them at mid-term and the final and to let them know that communication is open on both ends for them. I think that's really important, showing that there is some kind of presence there to assist them if they need anything or if they have any questions."

Participants in this study also acknowledged their responsibility in providing guidance and support to the preceptors, especially when decisions had to be made about student clinical performance. As one participant described:

"as the faculty advisor, I will work with the course professor, and it's the university people that would give the failing mark, it's not the preceptor that would actually fail the student, and I think preceptors are always worried about that because they might have expressed to me in the past, "well, I don't want to fail the student."

This participant further explained how she encouraged preceptors to document or keep anecdotal notes and to validate their observations by consulting agency staff in order to support their decision about the student's performance:

"If it's a situation where we're pretty sure that the student is not meeting the objectives then sometimes I've asked the preceptor to ask other members of the staff to ask too because the more documentation that we have about events or circumstances that student is not able to handle, that we would think that would be appropriate for their level, inappropriate behaviour, unprofessional behaviour, or adverse circumstances, then I think it's important that we have that documentation that will then support whatever grade level is assigned. So, that's what I've done with the preceptor."

\subsection{Guidance and support received from the edu- cational program}

In this study, faculty advisors were asked to describe the kind of support and guidance they were provided by educational institutions. The source and kind of support or guidance they received varied. As one participant recounted:

"Usually I receive really good guidance and support from the course professor that we work with mostly... [when] there is an issue with the student..."

Other participants sought guidance and support from the program coordinator or other colleagues:

"I speak not only to the preceptor but also to the program coordinator who often has knowledge about how that student is doing in other areas, so we try to take an overall look at things I guess, in order to give the student the benefit of the doubt. If that is possible..."

"I would discuss it with the co-coordinator, we would look at strategies together and get suggestions, maybe talk to other faculty with expertise in that area..."

"A great deal... Actually, my colleagues and our director... I've been assigned some time to actually step that up a little bit because we do recognize that clinical will go better for students if we ensure that our preceptors and our 
clinical instructors are well prepared to do what they have to do. So our department has assigned some additional time and energy in doing just that, developing a program which is quite in its infancy stage..."

\section{Discussion}

This study explored the preparatory and support needs of nursing faculty advisors involved in preceptorship-based courses and how they contended with a fourth year nursing student who was assessed as being unsafe in clinical practice by the preceptor.

All participants in this study reported being prepared at the graduate level. This finding is noteworthy since Master's level education has been identified as the expected preparation for a full-time faculty advisor role ${ }^{[34]}$ and essential for effective teaching and learning. ${ }^{[33,35]}$ In a study by Shanta, et al., ${ }^{[33]}$ for example, nursing faculty interns indicated, through a focus group, that graduate level education was essential for the development of specific competencies necessary for a faculty advisor role. According to Shanta et al., ${ }^{[33]}$ graduate level education for faculty advisors is important "to the individual educator's understanding of the conceptual building blocks of higher education, including the skill of developing and maintaining cohesive curricula, as well as the ability to develop effective program evaluation" (p.226). An earlier study by Riner and Billings ${ }^{[36]}$ in which the perceived needs of nursing faculty were explored in relation to development in teaching roles, found that faculty with no formal teacher education reported considerably higher levels of needs for understanding the educational processes, for example developing curricula, creating teaching learning situations, and using simulations to enhance critical thinking and problem solving.

While the preparation of faculty with graduate level education has been identified as essential for effective teaching and learning in nursing, ${ }^{[33,35]}$ the current tendency of employing individuals who are not academically prepared to teach as faculty advisors is not likely to decline in this period of faculty shortage. In addition, emphasizing the need for and effective transition into a new role is vital to the success of a faculty development program for faculty advisors. ${ }^{[33,37]}$ Rinner and Billings ${ }^{[36]}$ found that years of teaching and type of program or type of institution account for little difference in the need for faculty development. This implies that although participants in the current study had 1 $1 / 2$ years to 25 years of teaching in nursing education, and were located in different institutions (collaborative colleges and university) they would all benefit from faculty development programs.

Regarding role preparation in preceptorship, without exception all participants in this current study reported to have received no formal preparation. Rather, they described several informal ways through which they learned the faculty advisor role, including their previous experience as a clinical teacher, nurse, or preceptor; trial and error; reading course related documents; accessing web modules; and informal interaction with other faculty. This finding corroborates the findings of an earlier study on faculty advisor preparation for preceptorship ${ }^{[7]}$ and what has been highlighted in the literature. ${ }^{[9,23]}$ For example, in a study by Yonge, et al., ${ }^{[7]}$ when asked to explain how they were prepared for the preceptorship based-course, one faculty advisor reported that, "... just wing it...got the course outline and just went for it... had to figure it out on my own” (p. 211). Participants in Yonge et al.'s study further reported that due to lack of orientation to the course, most of them learned the role by trial and error or by observing experienced faculty advisors in the clinical setting. ${ }^{[7,9]}$

As previously alluded to, Scanlan ${ }^{[25]}$ identified five processes by which new clinical faculty learned their role. Trial and error was reported to be the main strategy that new faculty used as they attempted to make sense of the complex responsibility of teaching students. Other authors ${ }^{[38,39]}$ concur with the findings that preparation for the role of faculty advisor has mostly been through trial and error. Emerson, ${ }^{[39]}$ however, cautions that "learning by trial and error, testing an approach, and keeping or rejecting it based on the results is a difficult and stressing way of learning anything...", and that progress can be a "constant struggle for both faculty [advisor] and the student if this is the only method new faculty [advisors] have to rely upon" (p. 8).

Another process that some participants in this study used to enhance their new faculty advisor role was reading literature. Similar findings have been reported in previous studies by Scanlan ${ }^{[25]}$ and Yonge et al. ${ }^{[7]}$ In Yonge et al.'s ${ }^{[7]}$ study, for example, faculty who were prepared attributed it to: reading research, attending presentations or meetings, leading workshops, having previously engaged in preceptoring, interacting with other faculty, and being familiar with the setting. According to Scanlan, ${ }^{[25]}$ attendance at conferences, reading literature or participating in research can be valuable ways of stimulating faculty advisors' reflection and motivating them to think in new and different ways about teaching or their role.

Some participants in this study reported that they learned the faculty advisor role from their past experiences as clinical educators or nurses, preceptors, or having been a faculty member in a School of Nursing, a finding that was also reported by Yonge et al. ${ }^{[7]}$ and Scanlan. ${ }^{[25]}$ Other authors acknowledge that experience, past or present is a powerful means by which to learn how to teach and that new faculty advisors draw from those sources. ${ }^{[25,39]}$ Past experiences as a nurse and exemplar experiences such as having met and dealt with a specific challenging student situation, has also been found to enhance the confidence of new faculty advisors. ${ }^{[25,39]}$ Several authors ${ }^{[9,37,40]}$ also acknowledge, how- 
ever, that although the clinical expertise of faculty advisors is vital to nursing practice, clinical expertise alone is not sufficient preparation for the faculty advisor role. While the findings of this current study and the literature support the need for faculty development with regard to the transitioning of clinical nurses into faculty advisor roles, unfortunately, with the current shortage of nursing faculty and the fact that few academic nursing programs offer specializations in education, ${ }^{[41]}$ the trend of employing individuals as faculty advisors who are academically unprepared is likely to continue.

Participants described facilitation of student success as being fundamental to their faculty advisor role. Specific elements identified of this role cited by participants included facilitating learning, facilitating communication, evaluating, and assigning the final grade. These findings concur with the literature in which faculty advisors are perceived as being instrumental in informing preceptors about the principles of teaching and learning, including the evaluation process; offering guidance and support to the student and preceptor; and resolving conflicts as they arise. ${ }^{[3,7,9]}$

Open and ongoing communication is critical for the success of the preceptorship. Participants in this study also acknowledged the importance of communicating with preceptors. As custodians of the teaching-learning process, faculty advisors must ensure that the goals and objectives of the academic program are met, as well as maintain an open line of communication between the practice and academic settings. ${ }^{[2,4,5,8]}$ For example, Flynn and Stack ${ }^{[8]}$ acknowledge that facilitating preceptorship requires faculty advisors to be clear and open communicators. This facilitation will in turn assist faculty advisors in monitoring and evaluating student progress.

Meeting with the preceptor is especially important at the commencement of the preceptorship ${ }^{[2,7]}$ and desirable because preceptors have been found to express greater confidence in faculty advisors who are familiar to them. ${ }^{[12]}$ Therefore, while the literature acknowledges the challenges inherent within the faculty advisor role, including but not limited to lack of time, energy, resources and workload, ${ }^{[3,5]}$ it is important that faculty advisors ensure they remain in contact with the preceptor via telephone and/or email. This connection, as identified by the participants in this study, is perceived to be crucial to the success of the preceptorship. ${ }^{[2,3,5]}$ In the literature it is recognized that regular scheduled onsite visits can facilitate and strengthen the preceptor-advisor relationship and create more opportunities for dialogue and determining student progress. ${ }^{[4,7,9]}$ Regardless of whether the communication occurs during the site visits, by email or phone call, students and preceptors have consistently commented on how valuable they find faculty advisor presence throughout the preceptorship. ${ }^{[3,4,19]}$ Moreover, visits specifically designed for grading purposes, scheduled throughout the experience, rather than only at the end, might allow faculty advisors to monitor student progress over time, create a medium for feedback, and permit faculty advisors to assess preceptor teaching. ${ }^{[7,9]}$ As Bourbonnais and $\mathrm{Kerr}^{[3]}$ caution, however, educational institutions need to recognize the knowledge, time, and energy required of faculty advisors to create successful preceptorship experiences. It is interesting, nevertheless, that regardless of their knowledge and experience with the teaching and evaluation process, faculty advisors are expected to visit students and preceptors to provide guidance and evaluate performance.

This study also highlights the critical role faculty advisors play in providing support and guidance to the preceptors, especially when a decision has to be made about a student's clinical performance. This finding echoes those of earlier studies $^{[6]}$ that preceptors are more likely to make critical decisions about student performance when they are supported by faculty advisors. In their role, faculty advisors are expected to: a) respond to concerns and provide support to both the preceptor and student, and b) evaluate the student's clinical performance and assign a final grade..$^{[2,8,9,22]}$ The faculty advisor's role as an evaluator is important not only to the success of the preceptorship experience but also to patient safety. As gatekeepers to the profession, faculty advisors must ensure that only competent students graduate and enter the profession.

It is acknowledged that faculty advisors as well as preceptors need support and guidance from colleagues and educational institutions to carry out their role ${ }^{[42]}$ particularly to make critical decisions about student clinical performance and grading. In general, faculty advisors in this study had positive comments about the kind of support and guidance they received from colleagues and course professors and coordinators.

One faculty advisor in this study reported to have been pressured to pass a student who, based on the evidence, was considered to be unsafe. However, she believed that as a registered nurse, passing such students would compromise not only her professional license but also future patients. This finding affirms that the decision to fail a student is not taken lightly. It is the professional responsibility of faculty advisors to ensure that only students who have met the clinical course objectives and demonstrate competence in practice are allowed to graduate and become a nurse. ${ }^{[17,43]}$

\section{Limitations}

In this study, the limitations that the researchers recognize include the following: 1) the focus on a single collaborative $\mathrm{BScN}$ program in one province of Canada means that the results cannot be generalized to all faculty advisors. 2) The overreliance on interviews or self report data as the primarily data source may have increased bias or serious constraints to data generated. Although this study has generated 
valuable knowledge to support the need for role preparation and support for faculty advisors in preceptorship-based courses, future research with a larger sample is necessary to increase depth of knowledge in this area and to enhance transferability to other educational settings.

\section{Conclusion and recommendations}

Given the identified gap in the literature regarding the preparation of faculty advisors in their role in preceptorship-based courses, further research is needed in this area. Until now there has been little research carried out to explore faculty advisors' perceptions regarding the preparation they require when assuming their role in preceptorship. With this in mind and in light of the study findings, the following strategies to better support faculty advisors are suggested: 1) development of formal programs to provide initial and ongoing support for faculty advisors; 2) an on-line portal for discussion; 3) a faculty advisor/preceptor handbook to provide information on the key curricular structure and program ob- jectives; and 4) more time to be allocated for the faculty advisory role in order to make themselves readily available to preceptors and students.

In conclusion, the findings of this study confirm that the role of faculty advisor is pivotal to student success in the clinical teaching and learning context. Faculty advisors who lack preparation in the evaluation of student clinical performance, however, could compromise public safety when unsafe or incompetent students are passed through to graduation. ${ }^{[15,17,25]}$ Thus, faculty advisors need to be adequately prepared to be competent in both practice and teaching, oriented to their teaching role, and supported in order to graduate only those students who are safe and competent in practice. Faculty advisor preparation and ongoing professional development programs are essential to address significant issues, in particular preparation for preceptorship teaching, standards of performance, the evaluation process, managing unsafe or failing students, and resource development with preceptors.

\section{References}

[1] Canadian Association of Schools of Nursing. Clinical practice education survey 2003: CASN task force on clinical/practice education. Author: Ottawa. ON. 2004.

[2] Myrick F. Yonge O. Nursing preceptorship: connecting practice and education. Philadelphia: Lippincott Williams \& Wilkins, 2005.

[3] Bourbonnais F F, Kerr E. Preceptoring a student in the final clinical placement: reflections from nurses in a Canadian hospital. Journal of Clinical Nursing. 2007; 16(8): 1543-1549. PMID:17655543 http://dx.doi.org/10.1111/j.1365-2702.2006.01828.x

[4] Wade GH, Hayes E. Challenges and opportunities associated with preceptored community health clinical experiences. Public Health Nursing. 2010; 27(5): 459-467. PMID:20840716 http://dx.doi .org/10.1111/j.1525-1446.2010.00879.x

[5] Zawaduk C, Haeley-Ogden M, Farrell S, Lyall C, Taylor M. Educator informed practice within a triadic preceptorshop model. Nurse Education in Practice. 2013; 14(2): 214-219. PMID:24063791 http://dx.doi.org/10.1016/j.nepr.2013.08.008

[6] Luhanga F, Yonge O, Myrick F. Precepting an unsafe student: the role of faculty. Nurse Education Today. 2008a; 28(2): 227 231. PMID:17553601 http://dx.doi.org/10.1016/j.nedt. 2007.04 .001

[7] Yonge O, Ferguson L, Myrick F, Haase M. Faculty preparation for the preceptorship experience: the forgotten link. Nurse Educator. 2003; 28(5): 210-211. http://dx.doi.org/10.1097/0000622 3-200309000-00006

[8] Flynn JP, Stack MC. The role of the preceptor: a guide for nurse educators, clinicians, and managers, 2nd ed. New York: Springer Publication Company, Inc. 2006.

[9] Seldomridge LA, Walsh CM. Evaluating student performance in undergraduate preceptorships. Journal of Nursing Education. 2006; 45(5): 169-176. PMID:16722499

[10] Duffy K. A grounded theory investigation of factors which influence the assessment of students' competence to practice. London: Nursing and midwifery Council (NMC).2004.

[11] Lewallen LP, DeBrew JK. Successful and unsuccessful clinical nursing students. Journal of Nursing Education. 2012; 51(7): 398-
395. PMID:22533497 http://dx.doi.org/10.3928/0148483 4-20120427-01

[12] Luhanga F,Yonge O, Myrick F. Failure to assign failing grades: issues with grading the unsafe student. International Journal of Nursing Education Scholarship. 2008b; 5(1): 1-14. PMID:18384275 http://dx.doi.org/10.2202/1548-923X.1366

[13] Brown Y, Neudorf K, Poitras C, Rodger K. Unsafe student clinical performance calls for a systematic approach. Canadian Nurse. 2007; 103(3): 29-32. PMID:17410926

[14] Scanlan JM, Care WD, Gessler S. Dealing with unsafe students in clinical practice. Nurse Educator. 2001; 26(1): 23-27. http: //dx.doi.org/10.1097/00006223-200101000-00013

[15] Corlette J. The perceptions of nurse teachers, student nurses and preceptors of the theory-practice gap in nurse education. Nurse Education Today. 2000; 20(6): 499-505. PMID:10959139 http: //dx.doi.org/10.1054/nedt.1999.0414

[16] Yonge O, Ferguson L, Myrick F. Preceptorship placements in western rural Canadian settings: perceptions of nursing students and preceptors. Online Journal of Rural Nursing and Health Care. 2006; 6(2): 47-56.

[17] Yonge O, Myrick F. Preceptorship and the preparatory process for undergraduate nursing students and their preceptors. Journal for Nurses in Staff Development. 2004; 20(6): 294297. PMID:15586094 http://dx.doi.org/10.1097/0012464 5-200411000-00009

[18] Luhanga F, Myrick F, Yonge O. The preceptorship experience: An examination of ethical and accountability issues. Journal of Professional Nursing. 2010; 26(5): 264-271. PMID:20869025 http: //dx.doi.org/10.1016/j.profnurs.2009.12.008

[19] Sedgwick M, Yonge O. Students' perception of faculty involvement in the rural hospital preceptorship experience. International Journal of Nursing Educationa Scholarship. 2009; 6(1): 114. PMID:19799565 http://dx.doi.org/10.2202/1548-923 $\mathrm{X} .1833$

[20] Larocque S, Luhanga FL. Exploring the issue of failure to fail in a nursing program. International Journal of Nursing Education Scholarship. 2013; 10(1):115-122. PMID:23735436 http://dx.doi.o rg/10.1515/ijnes-2012-0037 
[21] Walsh CM, Seldomridge LA. Clinical grades:upward bound. Journal of Nursing Education. 2005; 44(4): 162-168). PMID:15862049

[22] Amiccuci B. What nurse faculty have to say about clinical grading. Teaching and Learning in Nurs. 2012; 7(2): 51-55. http: //dx.doi.org/10.1016/j.teln.2011.09.002

[23] Sedgwick M, Harris S. Critique of the undergraduate nursing preceptorship model. Nursing Research and Practice. 2012; 1-6. PMID:22649721 http://dx.doi.org/10.1155/2012/248356

[24] Heffernan C, Heffernan E, Brosnan M, Brown G. Evaluating a preceptorship programme in South West Ireland: Perceptions of preceptors and undergraduate students. Journal of Nursing Management. 2009; 17(5): 539-349. PMID:19575712 http://dx.doi.o $\mathrm{rg} / 10.1111 / \mathrm{j} .1365-2834.2008 .00935 . \mathrm{x}$

[25] Scanlan JM. Learning clinical teaching: is it Magic? Nursing and Health Care Perspectives. 2001; 22(5): 240-246. PMID:15957401

[26] Strauss A, Corbin J. Basics of qualitative research: Grounded theory procedures and techniques. Newbury Park, CA: SAGE Publications, Inc., 1990.

[27] Glaser BG. Theoretical sensitivity: Advanced in the methodology of grounded theory. Mill Valley, CA: Sociology Press, 1978.

[28] McCann T, Clark E. Grounded theory in nursing research: part 1methodology. Nurse Research. 2003; 11(2): 7-14. http://dx.doi .org/10.7748/nr2004.01.11.2.7.c5918

[29] Guba EG, Lincoln YS. Fourth Generation Evaluation. Newbury Park, California: Sage, 1989.

[30] Lobiondo-Wood G, Haber J. Nursing research in Canada: methods and critical appraisal for evidence-based practice, 8th ed.Toronto, ON: Mosby/Evolve, 2013. PMID:25032020

[31] Houghton C, Cassey D, Shaw D, Murphy K. Rigour in qualitative case-study research. Nurse Research. 2013; 20(4): 12-17. http: //dx.doi.org/10.7748/nr2013.03.20.4.12.e326

[32] Taylor BJ, Kermode S, Roberts KL. Researach in nursing and health care: evidence for practice, 4th ed. South Melborne, Victoria: Cengage Leraning Australia Pty Limited, 2011.

[33] Shanta LL, Kalanek CB, Moulton P, Lang T. Evidence for policy and regulation: a model to address development of unqualified faculty. Policy Politics Nursing Practice. 2011; 12(4): 224-
235. PMID:22438160 http://dx.doi.org/10.1177/1527154 411429863

[34] Penn BK, Wilson LD, Rosseter R. Transitioning from nursing practice to a teaching role. Online Journal of Issues in Nursing (OJIN), 2008; 13(3): Manuscript 3.

[35] Benner P, Sutphen M, Leonard V, Day L. Educating nurses: a call for transformation. San Francisco, CA: Jossey-Bass, 2010.

[36] Riner ME, Billings DM. Faculty development for teaching in a changing health environment: a statewide needs assessment. Journal of Nursing Education, 1999; 38, (9): 427-430. PMID:10609589

[37] Anderson JK. The work-role transition of expert clinician to novice academic educator. Journal of Nursing Education. 2009; 48(4): 203 208. http://dx.doi.org/10.3928/01484834-20090401-02

[38] Bartels JE. Preparing nursing faculty for baccalaureate-level and graduate-level nursing programs: role preparation for the academy. Journal of Nursing Education, 2007; 46(4): 154-158. PMID:17474484

[39] Emerson RJ. Nursing education in the clinical setting. St Louis, Missouri: Mosby/Elsevier, 2007.

[40] Halcomb EJ, Andrew S, Peters K, Salamonson Y, Jackson D. Casualisation of the teaching workforce: implications for nursing education. Nurse Education Today. 2010; 30(6): 528-532. PMID:19954868 http://dx.doi.org/10.1016/j.nedt.2009 .10 .022

[41] Scanlan JM, Care WD. Grade inflation: should we be concerned? Journal of Nursing Education. 2004; 43(10): 475-478. PMID:17152307

[42] Gaza EA. The experience of being a full-time nursing faculty member in a baccalaureate nursing education program. Journal of Professional Nursing, 2009; 25(4): 218-226. PMID:19616190 http: //dx.doi.org/10.1016/j.profnurs. 2009.01.006

[43] Hunt LA, McGee P, Gutteridge R, Hughes M. Assessment of student nurses in practice: A comparison of theoretical and practical assessment results in England. Nurse Education Today. 2012; 32(4): 351-355. PMID:21640448 http://dx.doi.org/10.1016 /j.nedt.2011.05.010 